\title{
Mechanical Properties Testing of P92 Welded Joints Prepared by Manual Metal Arc Welding
}

\author{
Petr MOHYLA, Lukáš HAVELKA, Karel KOUŘIL
}

\begin{abstract}
This article deals with the new results from measurement of mechanical properties of P92 welded joints. Tested welded joints of P92 steel were prepared using Gas Tungsten Arc Welding (GTAW) for root layer in combination with Manual Metal Arc Welding (MMAW) for filler layers. After the welding, the different modes of Post Weld Heat Treatment (PWHT) were made and the values of hardness, tensile strength and impact toughness of weld metal and Heat-Affected Zone (HAZ) were measured.
\end{abstract}

Keywords: Gas Tungsten Arc Welding; hardness; impact energy; Manual Metal Arc Welding; tensile strength; welding

\section{INTRODUCTION}

With development of new electrical devices, the worldwide energy consumption increases. In order to respond to this increasing consumption, it is necessary to build new energetic facilities and to improve their components. Many of these components are exposed to high temperatures and pressures of the water or steam located in the valve system. Higher values of temperatures and pressures are connected with the higher effectivity of power-plants and with the fuel saving and less amount of $\mathrm{CO}_{2}$ emission [1]

With increasing effectivity of power-plants it is necessary to use new modern materials. These materials should resist high temperatures and pressures and have to be very reliable, because every failure of the steel can have critical consequences. To prevent these failures the increased attention has to be paid to metallurgical composition of used steel, strength calculation of each part and to the joining of these parts - welding.

One of these creep-resistant materials is martensitic steel with the designation P92, which is very often used to build parts exposed to high temperatures and pressures of steam in supercritical blocks of the thermal power-plants [2]. Due to martensitic microstructure, welding of this steel is difficult. Especially, there is only little information concerning the influence of the welding method and the PWHT on mechanical properties of the heat-affected zone.

Welding is a special process of joining, because it causes thermal effects on the surroundings of welded joint and weld metal itself. These thermal changes lead to structural changes and degradation of material properties especially in heat-affected zone. Unwanted effect of welding can be partly removed by the heat treatment with the advantageous setup of the temperature and duration [3]. That is why the research of the post weld heat treatment modes has to be carried out. Based on the results from the experiment it is possible to evaluate the properties after the heat treatment and choose the mode with the best ratio of mechanical and elastic properties.

\section{EXPERIMENT}

Testing specimens (18 mm thick plates of P92 steel) were prepared using Gas Tungsten Arc Welding (GTAW) for root layer in combination with Manual Metal Arc
Welding (MMAW) for filler layers. Example of macrostructure of the weld can be seen in Fig. 1. The list of filler materials is given in Tab. 1, welding parameters can be seen in Tab. 2. Preheat temperature was $240{ }^{\circ} \mathrm{C}$, interpass temperature did not exceed $300{ }^{\circ} \mathrm{C}$. After welding the different modes of Post-Weld Heat Treatment were carried out (see Tab. 3).

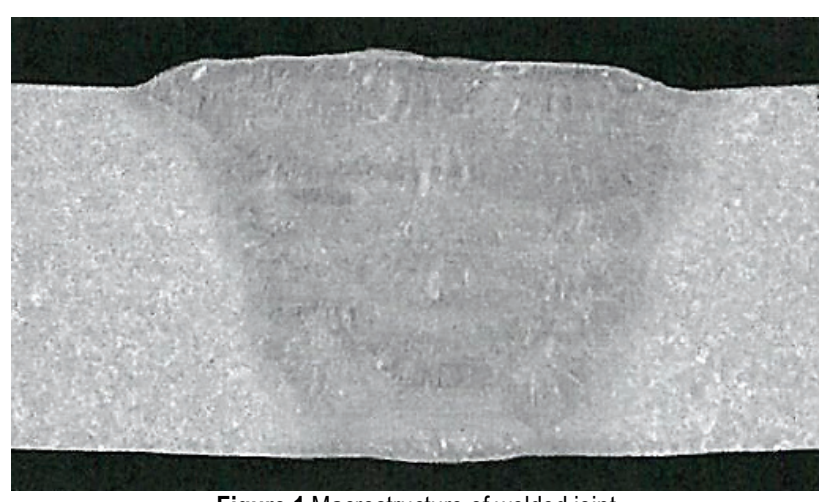

Figure 1 Macrostructure of welded joint

Table 1 List of filler materials

\begin{tabular}{|c|c|c|}
\hline Type & Designation & Manufacturer \\
\hline Wire & Thermanit MTS 616 & Böhler \\
\hline \multicolumn{3}{|c|}{ EN 12070-WZ CrMoWVNb 9 0,5 1,5 } \\
\hline Type & Designation & Manufacturer \\
\hline Gas & Argon 4.6 & SIAD \\
\hline \multicolumn{3}{|c|}{ EC: 231-174-0 } \\
\hline Type & Designation & Manufacturer \\
\hline Electrode & Thermanit MTS 616 & Böhler \\
\hline \multicolumn{2}{|c|}{ EN ISO 3580-A - EZ CroWVNb 9 0,5 2 B42H5 } \\
\hline
\end{tabular}

Table 2 Welding parameters

\begin{tabular}{|c|c|c|}
\hline $\begin{array}{c}\text { Welding } \\
\text { method }\end{array}$ & $\begin{array}{c}\text { Wire dimensions, } \\
\text { mm }\end{array}$ & Current, A \\
\hline 141 & $\varnothing 2$ & $90-100$ \\
\hline Voltage, $\mathrm{V}$ & Polarity & Heat input $Q, \mathrm{~kJ} / \mathrm{mm}$ \\
\hline $9-11$ & DC/- & $0,8-1,2$ \\
\hline $\begin{array}{c}\text { Welding } \\
\text { method }\end{array}$ & $\begin{array}{c}\text { Electrode } \\
\text { dimensions, } \mathrm{mm}\end{array}$ & Current, $\mathrm{A}$ \\
\hline 111 & $\varnothing 3,2$ & $100-115$ \\
\hline Voltage, $\mathrm{V}$ & Polarity & Heat input $Q, \mathrm{~kJ} / \mathrm{mm}$ \\
\hline $21-23$ & DC/ & $0,3-1,0$ \\
\hline
\end{tabular}


Table 3 Post weld heat treatment of welded joints

\begin{tabular}{|c|c|c|}
\hline $\begin{array}{c}\text { Duration of } \\
\text { PWHT, hours }\end{array}$ & Temperature 1 & Temperature 2 \\
\cline { 1 - 1 } 1 & \multirow{2}{*}{$730^{\circ} \mathrm{C}$} & $760^{\circ} \mathrm{C}$ \\
\cline { 1 - 1 } 2 & $\begin{array}{c}\text { Heating and cooling } \\
\text { rate: } 100^{\circ} \mathrm{C} / \text { hour }\end{array}$ & $\begin{array}{c}\text { Heating and cooling } \\
\text { rate: } 100^{\circ} \mathrm{C} / \text { hour }\end{array}$ \\
\cline { 1 - 1 } 3 & & \\
\cline { 1 - 1 } 5 & &
\end{tabular}

\subsection{Tensile Test}

Transverse tensile test of welds was done at temperature of $20{ }^{\circ} \mathrm{C}$. The minimal required value of tensile strength can be found in EN 10216-2 [4] - the values must lay in the range from 620 to $850 \mathrm{MPa}$ for steel P92. Graphical expression of average tensile strength - mode of post weld heat treatment dependence can be seen in Fig. 2.

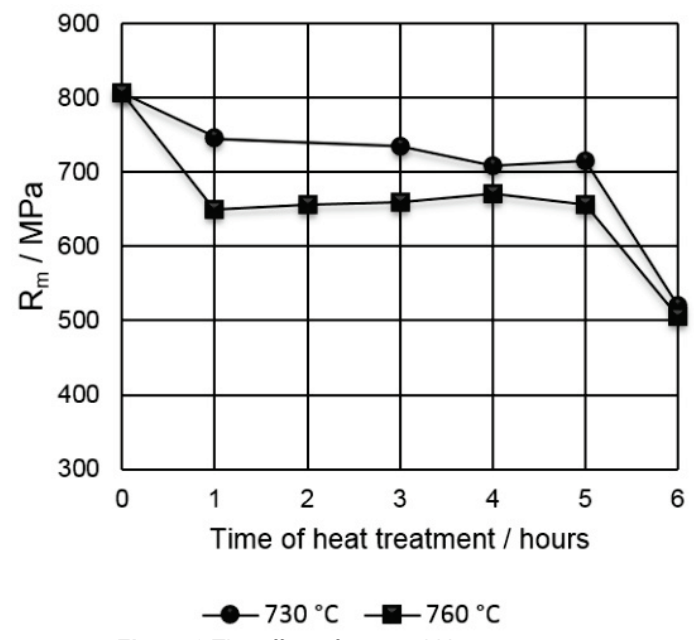

Figure 2 The effect of post weld heat treatment

Fig. 2 shows decreasing trend of tensile strength with increasing dwell on annealing temperature. The maximum value of tensile strength is $807 \mathrm{MPa}$ (without PWHT), the minimum value is $506 \mathrm{MPa}\left(760^{\circ} \mathrm{C} / 6\right.$ hours $)$. The values of tensile strength at heat treatment modes $730{ }^{\circ} \mathrm{C} /$ 6 hours and $760{ }^{\circ} \mathrm{C} / 6$ hours are not acceptable according to EN 10216-2 [4].

\subsection{Impact Test}

On all tested specimens the $\mathrm{V}$-notch was made.

- In a case of VWT $0 / 2$ the V-notch was situated in weld metal, in fusion line, $2 \mathrm{~mm}$ under the surface.

- In a case of VHT $2 / 2$ the V-notch was situated in heat-affected zone, $2 \mathrm{~mm}$ under the surface, $2 \mathrm{~mm}$ far from fusion line.

Impact test was made on specimens with standardized size $10 \times 10 \mathrm{~mm}$ according to EN ISO 9016 [5]. The required value of the impact energy according to EN 10216-2 is $27 \mathrm{~J}$ [4].

The effect of PWHT on average impact energy is captured in Fig. 3 and Fig. 4.

In Fig. 3 can be seen noticeable increase of impact energy - VHT $2 / 2$ in dwell time of 5 hours $\left(760^{\circ} \mathrm{C}\right)$. The maximum value in this time of tempering is $81 \mathrm{~J}$. Minimum value of the impact energy $(25 \mathrm{~J})$ was reached in 6 hours $\left(730^{\circ} \mathrm{C}\right)$. Without heat treatment the impact energy is not acceptable. The heat treatment modes $730{ }^{\circ} \mathrm{C} / 1$ hour, $760{ }^{\circ} \mathrm{C} / 1$ hour, $730{ }^{\circ} \mathrm{C} / 2$ hours and $730{ }^{\circ} \mathrm{C} / 6$ hours bring not acceptable results according to EN 10216-2 [4].

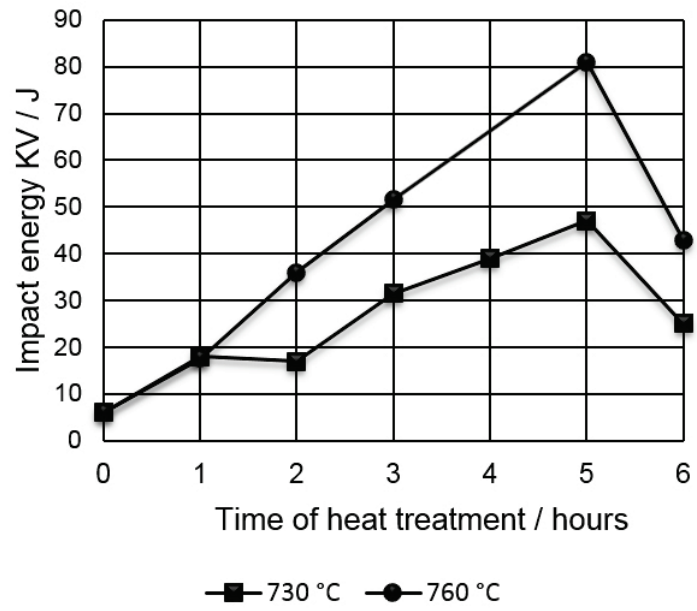

Figure 3 The effect of post weld heat treatment on average values of impact energy - VWT $0 / 2$

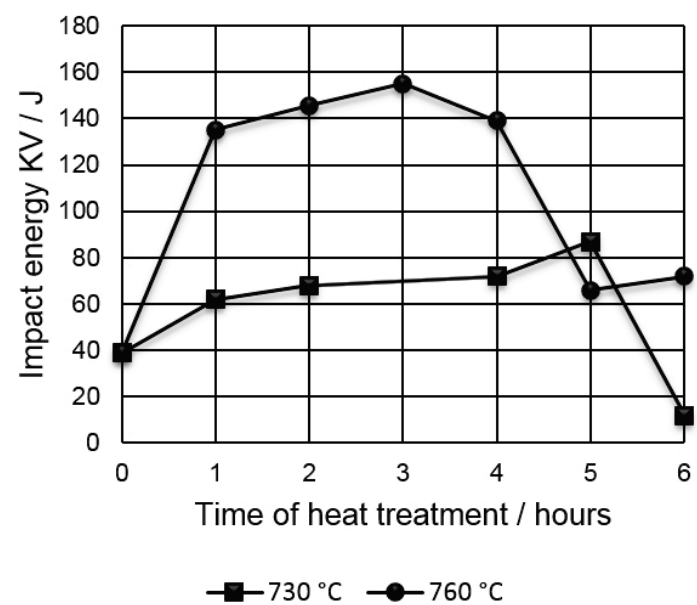

Figure 4 The effect of post weld heat treatment on average values of impact energy - VHT $2 / 2$

In Fig. 4 the values of impact energy were acceptable according to EN 10216-2 [4] - the only exception was heat treatment mode $730{ }^{\circ} \mathrm{C} / 6$ hours where the value was below the required boundary.

\subsection{Hardness}

Hardness testing was done with Vickers method using the testing load $10 \mathrm{~kg}$ (HV10). For the material group 6.4 the maximum value of hardness is $350 \mathrm{HV}$ according to the standard EN ISO 15614-1 [6]. The effect of heat treatment on average values of hardness in weld metal can be seen in Fig. 5 .

Hardness of weld metal is decreasing with the time of post weld heat treatment. The hardness without PWHT reaches $400 \mathrm{HV} 10$, which is not acceptable according to EN ISO 15614-1 [6]. 
The effect of post weld heat treatment on average values of hardness in coarse grained zone can be seen in Fig. 6.

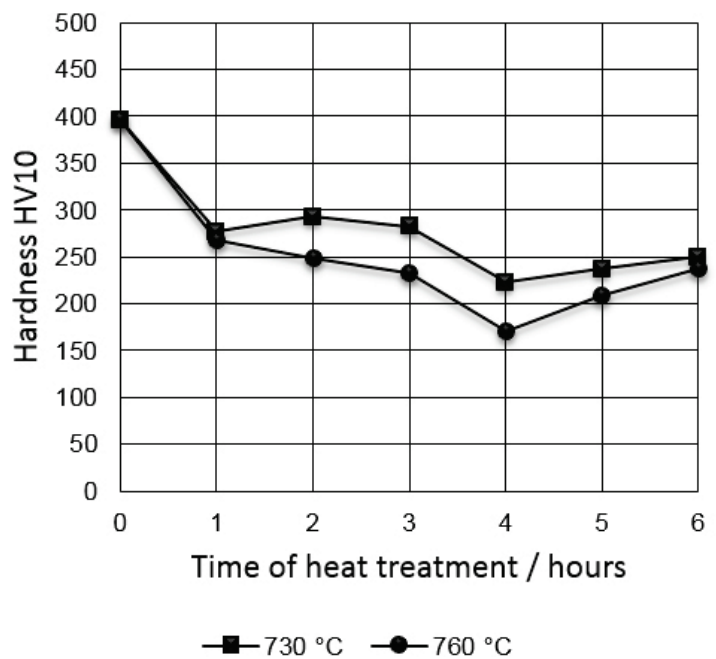

Figure 5 The effect of post weld heat treatment on average values of hardness measured in weld metal

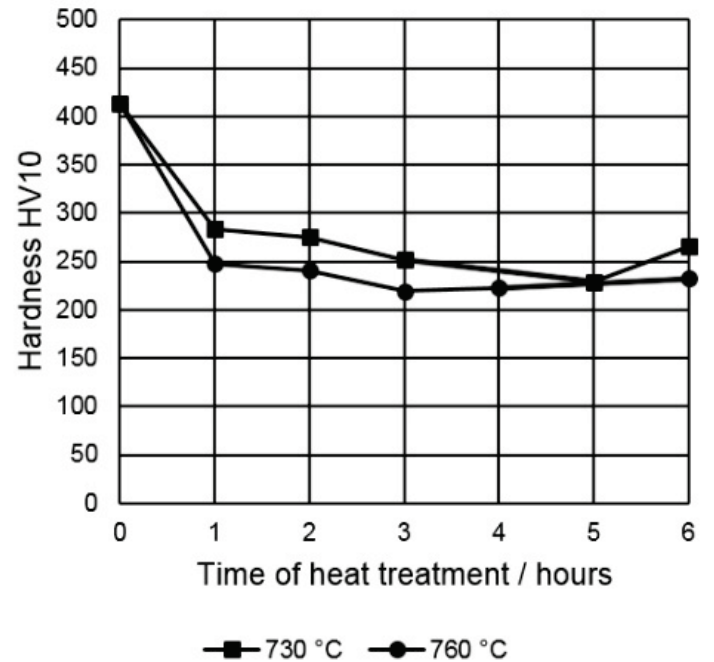

Figure 6 The effect of post weld heat treatment on average values of hardness measured in coarse grained zone of $\mathrm{HAZ}$

From the graphical expression in Fig. 6 for coarse grained zone it is clear that the values of hardness are decreasing with the time of the heat treatment. The hardness without post weld heat treatment reaches 450 HV10, which is not acceptable according to EN ISO 15614-1 [6].

Fig. 6 shows that the welds of P92 steel have to be heat treated and the time of heat treatment does not have too big influence on hardness.

\section{CONCLUSIONS}

P92 is progressive martensitic $9 \% \mathrm{Cr}$ steel, which can work in the ultra-supercritical conditions. It has very good mechanical properties and resistance against creep, nevertheless during welding the properties are devalued due to heat input. To improve the mechanical properties the post weld heat treatment is necessary. In order to find out the optimal heat treatment a series of experiments were made and the testing of tensile strength, impact energy and hardness was carried out.

Experiments showed that tensile strength has decreasing trend with increasing dwell on annealing temperature. All values of tensile strength except the modes of heat treatment $730{ }^{\circ} \mathrm{C} / 6$ hours and $760{ }^{\circ} \mathrm{C} /$ 6 hours are in the acceptable range from 620 to $850 \mathrm{MPa}$.

Impact energy in weld metal shows the increasing trend with the increasing time of heat treatment. Maximum value of impact energy was obtained in heat treatment mode $760{ }^{\circ} \mathrm{C} / 5$ hours. Minimum value of the impact energy was reached in 6 hours at $730{ }^{\circ} \mathrm{C}$. The impact energy of $\mathrm{P} 92$ weld metal is not acceptable without post weld heat treatment.

All the values of impact energy in heat affected zone were acceptable according to EN 10216-2 except of post weld heat treatment mode $730{ }^{\circ} \mathrm{C} / 6$ hours, where the impact energy was below the required boundary.

Values of hardness are decreasing with the time of heat treatment. The hardness without post weld heat treatment reaches not acceptable value in weld metal and in heat affected zone as well.

For achieving high strength and sufficient impact toughness can be recommended PWHT at $730{ }^{\circ} \mathrm{C}$ for 5 hours. To obtain maximum values of impact toughness while achieving a sufficient strength can be recommended PWHT at $760{ }^{\circ} \mathrm{C}$ for 3 hours.

\section{Acknowledgement}

This work was supported by the Ministry of Industry and Trade of Czech Republic in the project FT-TI3/206.

\section{REFERENCES}

[1] Heat Resistant Steels, Microstructure Evolution and Life Assessment in Power Plants. Thermal Power Plants Edited by Mohammad Rasul / Zheng-Fei Hu. Croatia : InTech, 2011, 195-226.

[2] Chen, Q. \& Scheffknecht, G. (2002). Boiler design and materials aspects for advanced steam power plants. Proceedings of COST Programme part II: Materials for Advanced Power Engineering, Vol. 21, 1019-1034.

[3] Koukal, J., Sondel, M. \& Schwarz, D. (2010). Correlation of Creep Properties of Simulated and Real Weld Joints in Modified $9 \%$ Cr Steels. Welding in the World, 54(1), R27R34. https://doi.org/10.1007/BF03263481

[4] EN 10216-2, (2008). Seamless steel tubes for pressure purposes - Technical delivery conditions - Part 2: Nonalloy and alloy steel tubes with specified elevated temperature properties, CEN.

[5] EN ISO 9016, (2012). Destructive tests on welds in metallic materials - Impact tests - Test specimen location, notch orientation and examination, CEN.

[6] EN ISO 15614-1, (2004). Specification and qualification of welding procedures for metallic materials - Welding procedure test - Part 1: Arc and gas welding of steels and arc welding of nickel and nickel alloys, CEN. 


\section{Contact information:}

Petr MOHYLA, Assoc. Prof., Ph.D., MSc.

VŠB-Technical University of Ostrava

Faculty of Mechanical Engineering

Department of Mechanical Technology

17. listopadu 15, 70833 Ostrava, Czech Republic

petr.mohyla@vsb.cz

Lukáš HAVELKA, MSc.

Flash Steel Power, a.s.

Martinovská 3168/48

72300 Ostrava - Martinov, Czech Republic

I.havelka@flashsteel.cz

Karel KOUŘIL, Ph.D., MSc.

Brno University of Technology

Faculty of Mechanical Engineering

Institute of Manufacturing Technology

Technická 2896/2, 61669 Brno, Czech Republic

kouril.k@fme.vutbr.cz 